\title{
Speech aspect of information behavior
}

\author{
Rafail Tazapchiyan* and Elena Shapovalova \\ Don State Technical University, 344000, Gagarin sq., 1, Rostov-on-Don, Russia
}

\begin{abstract}
This article is devoted to the analysis of information behavior based on the use of a natural language to obtain information by reading a literary text in a non-native language. One of the options for the result of such behavior is the so-called communication failures, which indicate obstacles in information retrieval. By communicative failures, the authors of the article mean a failure in the communication process, when the produced speech act does not fulfill its intended function, the addressee gets a greater degree of freedom to interpret the message sent to him, and his reaction may either not coincide with the one that was planned by the sender, or contradict it. In this case, culture acts as a regulator of information behavior as a set of values circulating in a social community. The mechanisms of the influence of culture on the mentioned behavior are stereotypes that exert a typifying influence on the activity of an individual. An attempt was made in the article to analyze the nature of the detected communication failures, as well as their typological description.
\end{abstract}

\section{Introduction}

Assessment of the level of a person's cognitive activity, as well as the development of measures to optimize it, is impossible without analyzing of the information behavior. By the latter, in the framework of this article, we mean the process of interaction of an individual with information environments in order to achieve a result that is useful for oneself. The originality of such behavior directly depends on the nature of the behavioral norms of the community into which this individual is integrated, the value orientations and role prescriptions inherent in this community.

For us, of particular interest will be the case of an individual receiving information by means of a language that is not native to him, which is often associated with difficulties that impede the receipt of the transmitted information, and in some cases make it impossible. Such cases are called communication failures. Their typology is determined by various factors. We will concentrate on analysis of the communication failures found when foreigners read a literary text in Russian.

Communication failures are understood as a failure in the communication process when the produced speech act does not fulfill its intended function, the addressee gets a greater degree of freedom to interpret the message sent to him, and his reaction either does not coincide with the one planned by the sender or contradicts it. We associate the possibility of avoiding such a state of affairs with the use of one form or another of methodological

\footnotetext{
* Corresponding author: rafail.tazapchiyan@mail.ru
} 
influence, which, in turn, requires an analysis of the nature of communication failures and the subsequent development of an adequate technology for overcoming them.

It should be recognized that communication failures, obviously, to some extent constantly accompany natural verbal communication. In the middle of the twentieth century A.M. Peshkovsky spoke about cases of difficult understanding as an obligatory companion of speech. He came to this conclusion after analyzing the cases of interpretation of judgments expressed by someone in different spheres of communication known to him, as well as numerous requests for clarification of this or that position. Experts refer to the most frequent cases of communication failures inaccurate statements, incorrectly constructed expressions, rather complex messages, all kinds of ways to reduce speech, as well as cases marked by a known approximation of the expression of information, as well as the implicitness of various information that is important for understanding the statement.

The most important issue in the study of the nature of communication failures is the attempt to classify them. It is generally accepted that the problem of their sufficiently complete cataloging has not yet received an exhaustive solution. This is due to the fact that this problem is closely related to the problem of creating models of communication processes. In addition, the situation is further complicated by the fact that specific communication failures are closely tied to various spheres of communication.

It seems to us that the communication failures mentioned by us can be conditionally divided into linguistic and extralinguistic. Speaking about linguistic difficulties, we mean cases of insufficient knowledge of the features of the system of the target language and the inability to use it to obtain the desired result, which we associate with the ability to construct and understand an unlimited number of linguistically correct sentences.

The purpose of this article is to analyze the influence of extarlinguistic factors on the process of language interaction in an intercultural environment and the causes of possible communication failures caused by these factors.

By extralinguistic factors, in this case, we mean culture. Culture is a highly comprehensive and multifaceted phenomenon. This circumstance was the reason for it's numerous and diverse interpretations in content. Based on the goals of our article, let us refer to the point of view of E.M. Vereshchagin and V.G. Kostomarov, who, analyzing culture as a product of social activity, propose to understand this phenomenon as a set of different orders of values circulating in a certain linguocultural community [1]. In this capacity, culture is the most important factor in the social regulation of an individual's behavior. The instrument of such regulation is social, and in our case, cultural stereotypes, which, through the actual presentation of socially sanctioned objective needs, have a stimulating typed effect on the consciousness of the individual. [4]

Since stereotypes represent a relatively stable and ordered image of a social object, their use in the practice of perceiving incoming information is characterized by two aspects: on the one hand, stereotypes play an essential role in the process of understanding data, since they reduce the time for responding to an incoming signal and thereby accelerate the process of understanding the information contained in the text, on the other hand, the stereotype does not always meet the requirement of accuracy and differentiation of the subject's perception of social reality, which in the practice of communication in an intercultural environment can seriously interfere with an adequate understanding of the perceived information. Such an interpretation of culture as a factor that directly controls the comprehension of the information of a work of art by the bearer of a different cultural tradition, is quite consistent with the understanding of culture as a model for interpreting what people say and do. [6] In this case, we can talk about two functions of culture that are most important for the topic we are discussing: the ability to streamline the flows of incoming and outgoing information, and secondly, to perform a restrictive function, defining a certain limit to the recipient's interpretive capabilities. 


\section{Materials and methods}

To analyze the nature of communication failures that are possible when foreigners understand a literary text in Russian, we invited them to read several short stories by A.P. Chekhov, written in the early period of his work ("You will chase two hares, you will not catch a single one" [7], "Which of the three?" [8]). After reading these texts, the students were asked to perform a series of tests, the purpose of which was to control reading comprehension. In addition, conversations were also held to clarify which elements of the literary text caused difficulties and which remained unclear.

Reading fiction in the target language is an integral, mandatory part of the professional training of foreigners studying at Russian universities, regardless of whether they are studying in the humanities or non-philological specialties, be it engineering or medicine. In addition to acquaintance with the culture of the country of the target language, reading literary texts also pursues practical goals related to the formation of the ability to consciously approach a work of art as the embodiment of the art of words, the ability to analyze linguistic means in connection with the content and the entire artistic structure of the text being read and more deeply comprehend the content with using linguistic and stylistic analysis. We inextricably link the achievement of such goals with the understanding by foreigners in the course of communication in Russian of a number of complex linguistic phenomena in their interconnection, which will ensure the possibility of their adaptation into the linguistic community that is relevant for them during their studies.

The imagery in a literary text is created not only by the language itself. Usually, linguistic and extralinguistic elements are so organically related to each other that the reader is not aware of one without the other. Extralinguistic means include the development of the plot, contrasts, parallelisms. However, these means go to the reader through the language.

After reading the aforementioned stories, foreign students were asked to take a test for understanding the information they contain. In addition, an interview was conducted, during which the subjects were asked questions to clarify the depth of their understanding of individual fragments of the literary text and to clarify their interpretations of the author's plot.

\section{Results}

Foreign students receiving higher education in Russian and mastering Level B-2 at the time of our work with them were invited to read several short stories by A.P. Chekhov, relating to the early period of his work, in the center of the plot of which is a description of life in Russian provincial cities of the late 19th century. Our choice of these particular stories is explained by the fact that, according to our observations, they are less often translated into foreign languages, do not have a screen version and for foreign readers are likely to present new material. After reading these stories, the students completed several test tasks, the purpose of which was to identify the level of completeness, accuracy and depth of reading comprehension. In addition, a conversation was held, during which we clarified the reasons for either insufficiently complete or misunderstanding of certain fragments of the text. As a result of these measures, we found out that all foreign students, having read the stories, quite fully understood the main storyline. However, a number of elements of the text that have a certain artistic value, serving to create an artistic image or atmosphere of what is happening, were in some cases not fully understood, and in some cases they were not understood at all.

The results of our analysis of the level of understanding of textual information are reflected in the Table 1. 
Table 1. Level of understanding of text

\begin{tabular}{|l|c|}
\hline \multicolumn{1}{|c|}{$\begin{array}{c}\text { Category of linguistic units contained in the text and } \\
\text { caused difficulty in understanding }\end{array}$} & $\begin{array}{c}\text { Quantitative presence in the } \\
\text { text }\end{array}$ \\
\hline Linguistic units, the understanding of which is approximate & $6 \%$ \\
\hline $\begin{array}{l}\text { Linguistic units, the understanding of which to refer to } \\
\text { reference books }\end{array}$ & $5 \%$ \\
\hline $\begin{array}{l}\text { Linguistic units knowledge of the meaning of which did not } \\
\text { provide text' understanding }\end{array}$ & $3 \%$ \\
\hline
\end{tabular}

In the first category, we attributed the difficulties associated with the perception of lexical units, the understanding of which was approximate. Their meaning was established by relying on the meaning of their constituent morphemes or by means of a dictionary. As an example, let us cite the nomination of the position of "state councilor", whose function, according to those who read the text, was to give advice. As a result of working with the dictionary, it was found out that "state councilor" in the Russian Empire meant a civil rank of the 4th class. Another example is the "volost clerk", when the students generally understood what functions constitute the essence of this profession, however, it was necessary to refer to the dictionary in order to find out the attribution of this position to a certain administrative-territorial unit within the Russian state in the described in the story period.

The same group included lexical units denoting the wives or widows of persons holding a certain position (general's wife, state councilor, teacher).

Another category in this category was lexical units, which, for obvious reasons, seemed to our readers unusual, but generally understandable. These include the forms of words characteristic of the speech of certain strata of Russian society at the end of the 19th and beginning of the 20th centuries (you know(s), unhappy(s), nothing(s)).

The next category includes cases of misunderstanding that make a communicative act unattainable. These cases are associated with difficulties when knowledge of the lexical meaning of a word or previously learned rules for using the grammatical forms of a word are insufficient to understand the meaning of what is being read. One of them, requiring a special commentary, was the appearance of foreign names in the text describing the Russian province of the late 19th century. In one of the texts read by foreign students, the same character within a short fragment is first called Ivan Gavrilovich, and then Jean. Our commentary boiled down to the fact that the desire of Russians, which began with the Age of Enlightenment, to join the common European cultural context and the resulting passion for foreign languages, introduced the use of foreign equivalents of names common in Russia at that time. It should be admitted that when reading the texts we proposed, some difficulties arose with the perception of the diminutive forms of the names common today (Dmitry - Mitya, Vladimir - Volya, Apollo - Apollosha). However, based on context, the students were able to correlate the full and short forms of names.

Particular difficulties were caused by a fragment in which one of the characters gives the following characterization to the heroine: "You are educated, scientist ... everything is noble." In this case, the word "noble" is used to show that the heroine received an education that is traditional for representatives of a higher social class. The students were familiar with only one variant of the meaning of this word - "worthy". A similar situation arose with a fragment of another story, where one of the characters, helping a married couple drowning in the river to get to land, says to them: "Shake (boltayte) your feet!" - he commanded, rowing with his left hand and dreaming of his brilliant future. " During the conversation it became clear that the verb "to shake" (boltat) was known to foreign students, however, only in one of its meanings - "to talk about something insignificant". 
We have included another example in the same category. This is a fragment in which the "singing of the nightingale" appears as a symbol of something beautiful and romantic, characteristic of European culture in general and Russian culture in particular. Foreign readers, however, perceived it exclusively as a description of a natural phenomenon associated with the production of sounds by a bird.

From the results of the test and the subsequent interview, it was established that certain difficulties were caused by a fragment in which one of the characters, a major with a significant fortune, when addressing his servant, calls him brother ("I suppose, brother, that not only men punish their wives "). It was clear from the text that both characters were not in consanguinity, and the use of the word "brother" seemed unmotivated to foreign readers. The latter explained that the address "brother" ("brother" in the text) is more familiar than friendly address to a man and is characteristic of the late 19th - early 20 th centuries.

Similar difficulties, which prevented the perception of the information of the fictional text, were caused by a fragment of a dialogue between the same two characters, in which the master (major) asks his servant what his wife is doing.

- "What is the lady doing?"

- "Sleep" (spiat)

Misunderstanding was caused by the answer of the servant, in which, when transmitting information about the state of affairs related to one person (the major's wife), a verb in the form of the 3rd person, plural was used. As a post-text commentary, it was clarified that the use of plural forms in relation to one person was associated with an emphasized expression of respect for that person.

Another fragment of the literary text caused difficulty, which can be attributed to communication failures, since it is associated with a lack of understanding of the information transmitted by the author. At the mention of a third person, the aforementioned servant asks the major if he is familiar with this person.

"There is a judge in the city, PyotrIvanovich ... If you please know?" (Isvolityznat)

The difficulties we indicated were associated with a question in which the verb "will" is used, which has the meaning "to want, to desire." However, in our fragment, the use of this word with an infinitive verb is more associated with an expression of respectful politeness.

\section{Conclusions}

The analysis of the work done by us allowed us to draw a conclusion. Communication failures are a kind of violation of information behavior. The reason for such failures, in particular, lies in the discrepancy between the stereotypes of speech behavior typical of representatives of different cultural traditions.

Culture as, firstly, a certain amount of knowledge recorded in the experience of an individual and, secondly, as a set of values that regulate his informational behavior, including speech, through stereotypes has a certain influence on the process of understanding the information contained in a literary text . However, with the selection of adequate methodological tools, this influence can be corrected.

\section{References}

1. Communication Failure in Dialogue and Discourse. Detection and Repair Processes (Ed. By R.G. Reilly, Amsterdam, 1987)

2. Amisha M. Mehta, Clinton S. Weeks, Ellen Tyquin, International Journal of Disaster Risk Reduction 2750, 101820 (2020) doi: 10.1016/j.ijdrr.(2020).101820 
3. Stephanie Wermelinger, Anja Gampe, M. Moritz, Daum, Journal of Experimental Child Psychology 4, 155, 84-94 (2016). DOI: 10.1016/j.jecp.2016.11.005

4. Sieb G. Nooteboom, Hugo Quené, Journal of Memory and Language 111, 104069 (2019) doi: 10.1016/j.jml.2019.104069

5. Sieb Nooteboom, Hugo Quené, Journal of Memory and Language 4(105), 43-59 (2018) doi: 10.1016/j.jml.2019.104069

6. Karin R. Humphreys, Heather Menzies, Johanna K. Lake, Evidence for learning Cognition 117(2), 151-165 (2010) doi: 10.1016/j.cognition.2010.08.006

7. A.P. Chekhov, You will chase two hares, you will not catch a single one (Complete works in 30 volumes, Moscow, 1974-1986)

8. A.P. Chekhov, Which of the three? (Complete works in 30 volumes, Moscow, 19741986).

9. Natalia Tuliakova, Russian Literature 111-112, $35-59 \quad$ (2020) doi: 10.1016/j.ruslit.2020.03.002

10. Sofie Henschel, Christel Meier, Learning and Instruction 44, 11-21 (2016) doi: 10.1016/j.learninstruc.2016.02.005

11. Jana Kusá, Jana Sladová, Miloš Mlčoch, Procedia - Social and Behavioral Sciences 112, 300-308 (2014) doi: 10.1016/j.sbspro.2014.01.1168

12. Marc Brosseau, Literature (International Encyclopedia of Human Geography, Second Edition, 2019).

13. Maria Rydell, Linguisticsand Education 45 (2018) doi: 10.1016/j.linged.2018.04.004

14. Dennis Day, Elisabeth Dalby, Journal of Pragmatics 126, 90-105 (2018) doi: 10.1016/j.pragma.2018.01.003

15. Natalia N. Sergeeva, Social and Behavioral Sciences 154, 250-253 (2014) doi: $10.1016 /$ j.sbspro.2014.10.145 